\title{
The benefits of enhancing the international mobility of undergraduate pharmacy students
}

Academics at University College London (UCL) School of Pharmacy have recognised the benefits of enhancing the international mobility of undergraduate pharmacy students, and have a history of providing research experiences to visiting, international students with the expectation that it will positively contribute to their pharmacy education in four key ways.

Firstly, studying abroad is expected to facilitate personal development. ${ }^{1-4}$ Students will have the opportunity to experience a different culture and lifestyle while living abroad independently. Studies have shown that students will feel more empowered, confident and independent ${ }^{1,4,5}$ and have an increased sense of initiative following their international experience. Secondly, studying abroad is expected to facilitate professional development. ${ }^{4}$ Students will have the opportunity to identify, compare and contrast different health-care practices between their host and home country, ${ }^{1,4}$ with the potential to learn unique and innovative ways of practicing pharmacy. It is anticipated that this exchange of good practice will expand and advance their academic knowledge, ${ }^{2-4}$ skills and competencies, enhance their understanding and awareness of global practices, ${ }^{5}$ and ultimately facilitate the development of a global pharmacy workforce. Thirdly, studying abroad is expected to enhance international mobility. ${ }^{3,5}$ Students will be able to make informed decisions regarding future work opportunities in the host country ${ }^{3}$ after having spent time in that country. International friendships ${ }^{4}$ can facilitate future visits to the host country and students may have increased motivation to consider future employment or training opportunities either in the host country or elsewhere abroad. ${ }^{4}$ Lastly, studying abroad is expected to increase employability and career prospects. ${ }^{3,4}$ The unique experience of these students would make them a more competitive candidate in the pharmacy workforce. It is 
anticipated that professional contacts made, will assist with future opportunities for employment, research and further education in the pharmacy field.

The project 'Evaluation of multi-compartment compliance aids in community pharmacies' was conducted in 2014 by a Spanish undergraduate pharmacy student at UCL School of Pharmacy. The project was designed to gather qualitative information via questionnaires, from community pharmacists around London, concerning their dispensing practices involving medicine organisers. This was an interdisciplinary, collaborative project that was developed in association with three academic supervisors from both the UCL School of Pharmacy research group 'Medication use, systems and practice' and 'Pharmaceutical materials and dosage form design'. In addition to the above expected benefits, the student highlighted a number of additional benefits of their international experience. They enjoyed meeting new people, improving their English language skills, and seeing significant improvement in their personal development. While living away from home, the student became more confident in making decisions independently and coping with difficult situations. As a result of this, the student felt more independent, mature, and experienced increased self-esteem. Exposure to new cultures and people increased the student's global awareness and opened their mind to understanding differing points of view. Additionally, they felt that their career and research prospects had been strengthened.

It is hoped that by sharing positive experiences of enhancing student mobility, more academic institutions can be encouraged to facilitate undergraduate pharmacy student international placements and as a result, student mobility will remain an important focus of higher education policy. The benefits of international mobility programmes can ultimately contribute to developing a competent and confident global pharmacy workforce. 


\section{References}

1. Lee NJ. The impact of international experience on student nurses' personal and professional development. Int Nurs Rev. 2004;51(2):113-22.

2. Kyvik S, Karseth B, Remme JA, Blume S. International mobility among Nordic doctoral students. Higher Education. 1999;38(4):379-400.

3. King R, Ruiz-Gelices E. International student migration and the European 'year abroad': effects on European identity and subsequent migration behaviour. International journal of population geography:IJPG. 2003;9(3):229-52.

4. Green BF, Johansson I, Rosser M, Tengnah C, Segrott J. Studying abroad: A multiple case study of nursing students' international experiences. Nurse Educ Today. 2008;28(8):981-92.

5. Hadis BF. Why are they better students when they come back? Determinants of academic focusing gains in the study abroad experience. Frontiers: The interdisciplinary journal of study abroad. 2005;14(Aug):57-70.

Julia Fiona-Maree Gilmartin, ${ }^{1,2^{*}}$ B.Pharm (Hons), GCPP, PhD, AFHEA(UK), MPS julia.gilmartin@monash.edu

Bahijja Tolulope Raimi-Abraham, ${ }^{3}$ MPharm, PhD

Isabel Espadas-Garcia ${ }^{4}$

Mine Orlu-Gul, ${ }^{3}$ LD, MSc, DPhil 
${ }^{1}$ Research Department of Practice and Policy, University College London School of Pharmacy, London, United Kingdom

${ }^{2}$ Department of Epidemiology and Preventive Medicine, School of Public Health and Preventive Medicine, Monash University, Victoria, Australia

${ }^{3}$ Department of Pharmaceutics, University College London School of Pharmacy, London, United Kingdom

${ }^{4}$ Universidad Miguel Hernández de Elche, Avenida de la Universidad, Alicante, Spain

* Corresponding Author 